\title{
Mapa Mental como ferramenta para designers
}

\author{
Mind Map as tool for designers
}

RICALDONI, Thaís Falabella; Mestranda; Universidade do Estado de Minas Gerais thaisfalabella@gmail.com

FONSECA, Luíza Antunes; Graduanda; Universidade do Estado de Minas Gerais

luizaaf6@hotmail.com

REZENDE, Edson José Carpintero; Doutor; Universidade do Estado de Minas Gerais

edson.carpintero@gmail.com

\section{Resumo}

Atualmente o design está inserido em projetos multidisciplinares, em que suas competências e habilidades são requeridas, destacando-se a empatia, a criatividade e a visão de inovação. A inserção dos designers no variado mercado de trabalho exige que essas capacidades dos profissionais sejam desenvolvidas, utilizando, para tal, métodos e ferramentas. Uma dessas ferramentas que tem potencial de colaborar com o processo de design é o mapa mental. Assim, esse artigo se propõe a investigar a aplicação dos mapas mentais nos processos de design, por meio de uma revisão da literatura sobre a ferramenta e sobre a área do design. Além disso, foi realizado um estudo de caso da aplicação do mapa mental dentro de um projeto de design conduzido em um estabelecimento prisional humanizado. Observa-se que o uso dessa ferramenta pode ser positivo na construção de um processo de design em grupo, auxiliando principalmente nas suas fases iniciais.

Palavras Chave: Mapa mental; Design; Ferramentas e APAC.

\begin{abstract}
Currently the design is inserted in multidisciplinary projects, in which their skills and abilities are required, emphasizing empathy, creativity and the visionary. The insertion of the designers in the varied labor market demands that these capacities of the professionals to be developed, using, for such, methods and tools. One of these tools that has the potential to collaborate with the design process is the mind map. Thus, this article proposes to investigate the application of Mind Maps in the design processes, through a review of the literature about the tool and the area of design. In addition, a case study of the application of the mind map was carried out within a design project conducted in a humanized prison. It is observed that the use of this tool can be positive in the construction of a group design process, assisting mainly in its initial phases.
\end{abstract}

Keywords: Mind map; Design; tools and APAC. 


\section{Introdução}

O design pode ser caracterizado como "um processo que busca soluções criativas e inovadoras para atender às características dos produtos, às necessidades do cliente e da empresa de forma sintonizada com as demandas e oportunidades do mercado" (TEIXEIRA, 2009, p. 4). Hoje em dia tem-se um novo olhar para o design, em que muitas empresas e corporações buscam esses profissionais com o objetivo de utilizar seu potencial criativo e técnicas de empreendedorismo e inovação.

Para Franzato (2011), a utilização do design nas organizações pode promover estratégias para inovar, reduzir custos e deixar os clientes satisfeitos. O autor afirma ainda que o design, no contexto atual, é considerado um elemento estratégico para as organizações, pois seu sistema de competências e conhecimentos cada vez mais abrangentes, são úteis nas atividades organizacionais de qualquer empresa.

Uma das ferramentas que podem ser utilizadas pelos designers para enriquecer o processo criativo e inovador é o mapa mental. Segundo Hermann e Bovo (2005), o mapa mental é uma excelente "ferramenta" que complementa nossa linguagem escrita, enriquece nossa expressão criativa e desenvolve mais flexibilidade e recursos mentais.

As características dessa ferramenta, como a visualização das informações e sua facilidade de aplicação em grupo, fazem dela interessante para o processo de design. Assim, essa pesquisa tem como objetivo analisar o potencial do mapa mental ser aplicado como ferramenta por designers. Para tal, foi realizada uma revisão da literatura sobre os temas e um estudo de caso que analisa a aplicação da ferramenta durante a condução de um processo de design realizado em um estabelecimento prisional humanizado, com participação dos apenados. De acordo com Silva e Menezes (2005), pesquisa do presente artigo pode ser considerada de natureza aplicada, uma vez que busca gerar conhecimentos específicos para a aplicação prática, além de contribuições para o avanço científico. Ela tem uma abordagem qualitativa, por realizar uma análise subjetiva das informações encontradas e aprofundada em um caso de aplicação específico.

$\mathrm{Na}$ etapa de revisão da literatura foi feito um levantamento de estudos correlacionados na base de periódicos da Capes. Os estudos foram selecionados, tendo como critério o potencial de colaboração com o objetivo de pesquisa proposto, e analisados, buscando interseções entres as áreas pesquisadas. Na etapa de estudo de caso foi realizada uma oficina de aplicação do mapa mental, em que as observações foram registradas em um diário de campo, os blocos adesivos (post-its) utilizados no processo foram coletados e uma síntese da ferramenta resultante em modelo digital foi confeccionada. Desse modo, o primeiro subtítulo deste artigo apresenta uma contextualização sobre o processo de design e sua aplicação na atualidade, o segundo apresenta os fundamentos e características dos mapas mentais, e o último aborda a experiência de aplicação do mapa mental no caso supracitado.

\section{Design}

A economia global, o aumento da competitividade no mercado e a velocidade das mudanças tecnológicas e comportamentais têm exigido cada vez mais que as empresas sejam inovadoras. Segundo Bonini e Sbragia (2011), o design ganha destaque no desenvolvimento de inovações pela sua habilidade de gerir problemas complexos, estimular a criatividade e direcionar para a solução de problemas. Tais características fazem do designer um agente promissor nesse 
contexto de busca pela inovação.

O designer atua na mediação entre diferentes áreas do conhecimento, integrando pensamento e prática, propiciando assim o desenvolvimento de inovações (KRUKEN, 2009). De acordo com Franzato (2011), existem atualmente processos de inovação administrados pelo design, que o reconhecem como elemento estratégico por seu sistema de conhecimento e competências, além da sua capacidade de compreender instrumentos essenciais para alcançar a inovação. Diante disso, o designer tem se tornado cada vez mais relevante e necessário, sendo considerado um profissional capaz de elaborar estratégias de negócios para o mercado.

Segundo Avendaño (2011), o design já é percebido como responsável pelo diferencial inovador e de competitividade dos produtos. É imperativo a formação de profissionais que pensem o design muito além da sua estética e da própria emoção. É necessário pensar a ideia como gestão, junto com o empresário, em prol do reconhecimento da sua marca e sucesso da sua empresa. Como tratado por Brown (2009), uma vez que popularizado, o pensamento projetual do design pode ser disseminado para as organizações, influenciando sua administração e as direcionando para a inovação.

"O design é o que vincula a criatividade e a inovação. Ele forma ideias para tornar proposições práticas e atraentes para usuários ou clientes. O design pode ser descrito como criatividade implantada para um fim específico" (THE COX REVIEW, 2007). O processo de design utiliza, muitas das vezes, uma metodologia para propor possíveis soluções a problemas complexos em seus projetos. Ela se baseia em expandir o entendimento sobre o desafio enfrentado e, a partir de então, refinar o conhecimento adquirido para encontrar novas associações e significados (PINHEIRO; ALT, 2011). Esse método se chama Duplo Diamante e é empregado em muitas empresas.

Desenvolvido em 2005 pelo Design Council, órgão público do Reino Unido, o duplo diamante é uma maneira gráfica simples de descrever e identificar como o processo de pensamento do design funciona e é aplicado. O pensamento do design sugere que deve-se gerar opções a fim de encontrar novas possibilidades ao invés de escolher primeiro um caminho e a partir dele gerar opções (PINHEIRO; ALT, 2011, p. 43). Ele é composto por quatro etapas: descobrir, definir, desenvolver e entregar, como apresenta a Figura 1: 
Figura 1 - O diagrama do duplo diamante

\section{O diagrama do duplo diamante}

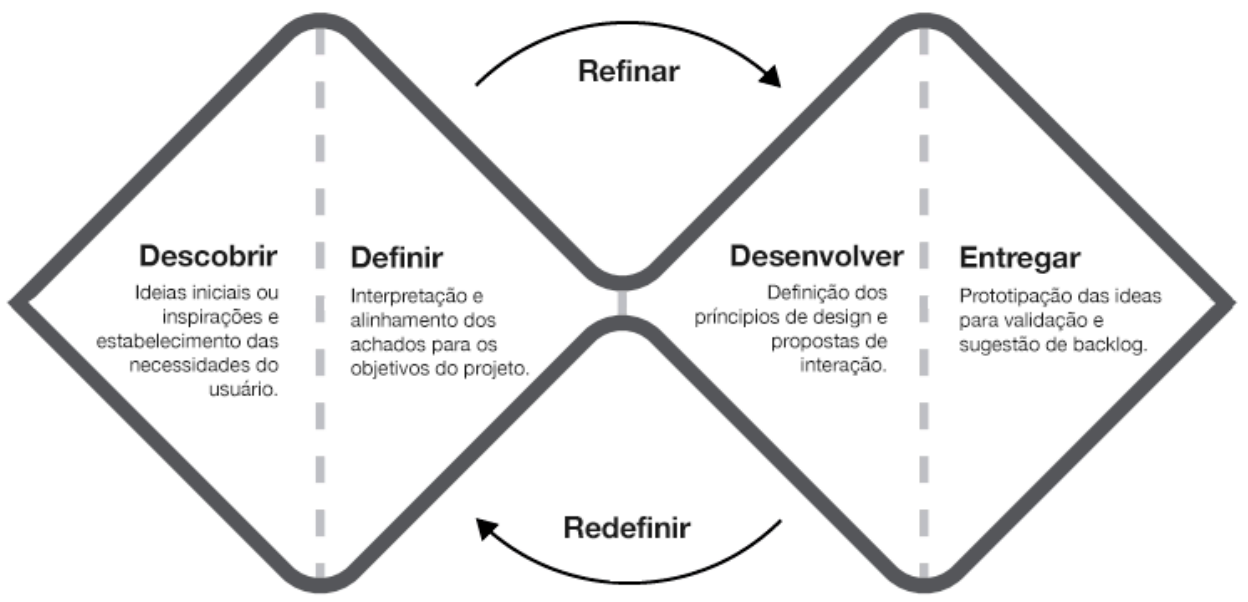

Fonte: https://paxliber.weebly.com/dt/como-os-designers-pensam-o-duplo-diamente (2016)

Conforme o Design Council (2007), a primeira etapa é a de descobrir, e se inicia a partir de uma ideia identificada com base nas necessidades do usuário. Na etapa definir, tem-se como objetivo, a interpretação das necessidades dos usuários e o alinhamento aos objetivos do negócio, reunindo requisitos que servirão de base para as próximas etapas. Na terceira etapa, desenvolver, as soluções de projeto são previamente criadas a partir do design e são desenvolvidas e testadas com as outras áreas da empresa. Na última etapa, a de entregar, o produto ou serviço resultante do processo é finalizado e segue para o mercado.

É importante para o designer conseguir canalizar essa massa de ideias, para que elas possam ser analisadas e assim direcionadas para o foco de um problema. A partir disso, faz-se necessário a utilização de ferramentas que o auxiliem a organizar e sintetizar as informações adquiridas. Uma ferramenta que pode ser utilizada para tal fim, é o mapa mental, que para Silva (2009), é uma ferramenta que permite a memorização, organização e representação da informação a fim de facilitar os processos de aprendizagem, administração e planejamento organizacional, assim como, a tomada de decisão.

\section{Mapas Mentais}

Na década de 70, Tony Buzan, psicólogo inglês, pesquisador, auditor e consultor educacional, se tornou sistematizador e desenvolvedor dos chamados mapas mentais em seu livro Use your head. Ele se tornou autoridade mundial sobre aprendizagem, memória e uso do cérebro, palestrando em todo o mundo e produzindo uma série de livros traduzidos para mais de 30 línguas. Buzan é o principal autor e propagador da ferramenta mapa mental.

Segundo Buzan (2009), a ferramenta foi criada como método de aprendizado e memorização quando ele ainda era estudante. Na época, ele tentava descobrir um meio de fazer as anotações de modo mais eficiente. Hoje, passados mais de 40 anos, pessoas no mundo inteiro utilizam a ferramenta com o mesmo fim, mas também em diversas outras aplicabilidades que 
foram sendo descobertas.

Em sua obra "Mapas Mentais", Buzan (2009), define o mapa mental como uma ferramenta dinâmica e estimulante que contribui para que o pensamento e o planejamento se tornem atividades mais inteligentes e rápidas. $O$ autor afirma também, que os mapas mentais são um método de armazenar, organizar e priorizar informações (em geral no papel), usando palavraschave e imagens-chave, que desencadeiam lembranças específicas e estimulam novas reflexões e ideias. Para Hermann e Bovo (2005), "mapa mental é essencialmente um diagrama hierarquizado de informações, no qual podemos facilmente identificar as relações e os vínculos entre as informações".

De acordo com Amoretti e Tarouco (2000), o mapa mental auxilia a organizar as informações, deixá-las visuais, de forma que as conexões e vínculos entre os conceitos sejam facilmente identificados. Trata-se de uma abordagem não linear do encadeamento de informações, ideal para estruturar pensamentos e gerar ideias.

A principal linguagem do cérebro se encontra nos sentidos, associação de imagens, cores, ideias e palavras-chave. A partir disso, Buzan (2009) identificou que a melhor forma de se construir um mapa mental seria utilizar essa linguagem do cérebro em formato de um neurônio e esquematizá-la livremente no papel, como ilustra a Figura 2. Tem-se o mapa mental como um resumo em um único plano de um gráfico da própria esquematização mental, com ramificações ao redor de um conceito central (palavra ou imagem), em que cada ramo contém outros importantes conceitos-chave, que são adicionados como ramificações sucessivas de forma hierárquica, mas não rígida, gerando uma sub-ramificação que é sempre dependente de um ramo principal. Cada ramificação contém uma palavra ou imagem que colabora para a construção significativa do conceito central.

Figura 2 - A estrutura do mapa mental

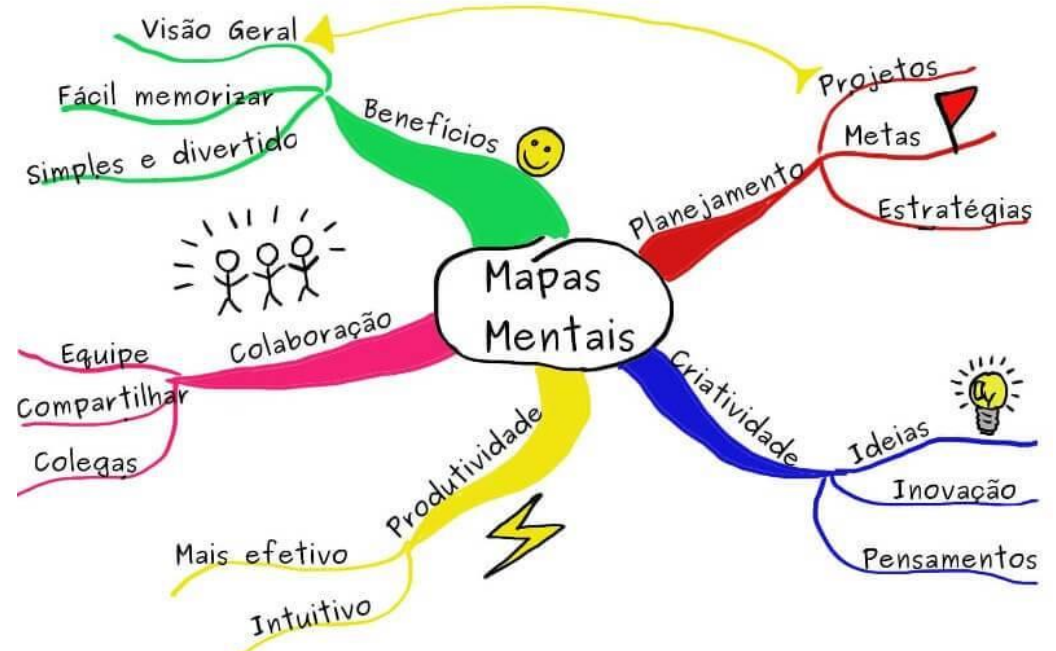

Fonte: https://oraculoti.com.br/2017/08/11/aplicativos-gratuitos-para-criar-mapas-mentais/ (2017)

O segredo da eficiência do mapa mental está em sua forma e configuração dinâmicas. Com o formato de um neurônio, os mapas mentais são projetados para estimular o cérebro a fazer associações. As associações são fatores importantes para favorecer a memória e a criatividade. 
Elas são criadas pelo cérebro a partir da conexão das informações (Buzan, 2002).

Em um mapa mental, conforme Buzan (2009), para as associações se realizarem, é importante a utilização de setas, cores e códigos. As setas guiam o olhar de modo que as palavras ou imagens-chave se unam e sugiram movimento, o que torna a memória e as lembranças mais eficazes. As cores são uma das formas mais poderosas de intensificação da memória e da criatividade. A escolha de uma cor para cada ramificação potencializa um acesso rápido à informação necessária e ajudará na lembrança com maior facilidade. Já os códigos permitem a realização de conexões instantâneas dentro do mapa mental, por mais afastadas que elas estejam. Quanto mais claro você for, melhor será a sua compreensão e a das outras pessoas. Anotações rabiscadas confundem a memória e atrapalham o entendimento, o que inibe a habilidade que 0 cérebro tem de fazer associações.

Assim como os neurônios, os mapas mentais são como estruturas radiais, o que sugere que as informações neles contidas são dispostas em raios. Segundo Buzan e Buzan (1994), a origem para essa representação radial está, na forma como o cérebro funciona, já que pensa-se radialmente (radiant thinking). Com isso, o mapa mental pode ser entendido como a representação externa do pensamento radial, que sempre irradia de uma imagem central. Cada imagem ou palavra se torna por si só um subcentro de associação. A estrutura radial dos mapas mentais estimula a memória, a recuperação de informações e a criatividade do indivíduo, manifestada na habilidade de estabelecer e perceber conexões por meio das palavras, imagens, cores, códigos e dimensões empregadas no mapa.

Segundo Buzan (2009), essa não linearidade dos mapas mentais, possibilitam inesperadas alterações de direção e de caminhos que o cérebro faz pela associação de ideias. Pode-se afirmar que os mapas mentais propõem ao cérebro o pensar diferente e, assim, aumentam a possibilidade de produzir alguma informação inédita ou até mesmo resgatar memórias esquecidas. Buzan (2002) ainda diz que o cérebro humano é um caldeirão de criatividade e tudo que ele precisa é das ferramentas corretas para que esta criatividade seja liberada, ou melhor aproveitada. Sendo assim, "o mapa mental é um recurso que canaliza a criatividade, porque utiliza todas as habilidades a ela relacionadas, sobretudo 'a imaginação, a associação de ideias e a flexibilidade" (ONTORIA PEÑA; LUQUE; GÓMEZ, 2008, p.25). Os mapas mentais são muito eficientes para o entendimento de contextos e criação de projetos. Podem ser considerados por Amoretti e Tarouco (2004) um método intuitivo, interessante e atraente.

De acordo com Dell'Isola (2012), os mapas mentais são altamente recomendados na elaboração de projetos dada a sua capacidade de síntese e apelo visual, conforme exemplifica a Figura 3 abaixo. Eles mantêm a equipe criativa e permitem que sua criatividade se desenvolva ao máximo. Logo, os mapas mentais podem ser úteis para designers, como meio de despertar a criatividade e gerar ideias. 
Figura 3 - Exemplo aplicação mapa mental

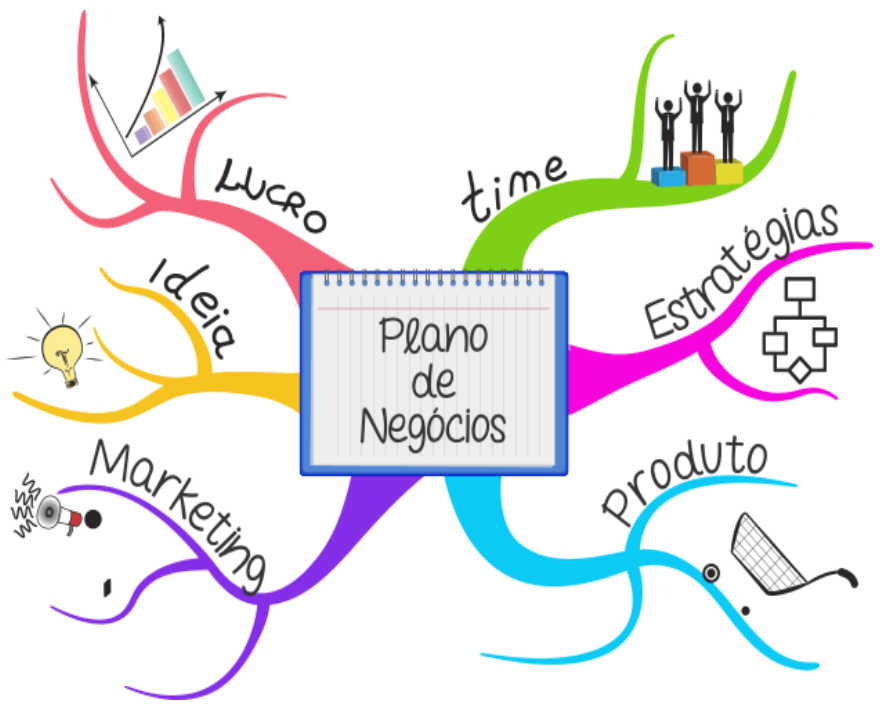

Fonte: http://estudoacelerado.com.br/o-que-e-um-mapa-mental/ (2016)

Conforme Buzan (2009), os mapas mentais nos permitem planejar vários aspectos da vida com autoconfiança. Eles são recursos de comunicação, resolução de problemas, imaginação, educação, revisão, gerenciamento do tempo e uso da memória. Também podem ser criações artísticas por si mesmos. Os mapas mentais podem ser usados para todo e qualquer propósito na vida. As aplicações são diversas: na escola, no trabalho, em casa, na vida social, no desenvolvimento de ideias criativas, no gerenciamento, planejamento e elaboração de projetos, na geração de ideias, gerenciamento de tempo, formação de equipe e apresentações.

Ainda segundo Buzan (2009), é certo que planejar informações com eficiência aumenta a probabilidade de ser bem-sucedido. A organização do pensamento contribui para um melhor desenlace e fluidez do pensamento criativo, sendo este fundamental para a resolução de problemas. Os mapas mentais contribuem inestimavelmente para a solução de problemas, inclusive dentro de um projeto. O problema, sendo esse definido por Eden (1983) "como uma situação onde alguém deseja que alguma coisa seja diferente de como ela é, e não está muito seguro de como obtê-la", faz dos mapas mentais uma ferramenta útil, quando objetivos e metas não estão muito claros e necessitem de apoio à definição do problema. Como Belluzzo (2007) afirma, os mapas mentais são considerados importantes ferramentas gráficas que classificam, representam e comunicam as relações, servindo como ponto de referência para tomadas de decisão.

Buzan (2009) também aponta sobre a capacidade de contribuição para a criatividade que o mapa mental pode promover quando se quer ser mais criativo, utilizando-o como meio de se obter ideias e soluções. Diante dos processos de armazenagem e organização de informações, ele amplia sua visão diante de alguma situação e logo tem-se um esquema detalhado de um conceito, facilitando assim a visualização e obtenção de uma solução ou ideia criativa.

Além de serem desenvolvidos individualmente, os mapas mentais podem ser aplicados em trabalhos de equipes, sendo assim muito úteis dentro de uma empresa ou organização. Quando elaborado em grupo, o mapa mental incorpora uma ferramenta chamada brainstorming, que segundo Nunes (2008), é conhecido como tempestade de ideias. É um método coletivo de geração 
de novas ideias, realizado por meio da contribuição e participação de várias pessoas inseridas num determinado grupo. De acordo com Cain (2012), neste método não se pode julgar ou criticar as ideias dos participantes, deve-se expor todas as ideias que surgirem, ter o máximo de ideias possíveis ou construir uma ideia em cima das demais geradas pelo grupo.

Portanto, Buzan (2009) afirma que os mapas mentais classificam o desenvolvimento de ideias surgidas e sistematizam as informações e palavras recolhidas, proporcionando uma visão mais clara e equilibrada do que foi discutido e sugerido. Há, no desenvolvimento em grupo, uma série de vantagens quando aplicados em reuniões. Há a contribuição significativa de todos, nenhum membro do grupo é ignorado e as sugestões são acrescentadas constantemente. Em um grupo, as ideias são compartilhadas, todos os participantes entendem os pontos de vista dos outros; todos os colaboradores se encontram em um mesmo nível de importância; a energia, o entusiasmo e a cooperação entre os membros são aumentadas por terem todas as contribuições individuais incluídas; há um maior entendimento das decisões tomadas e lembrança das mesmas; as reuniões se tornam mais rápidas e produtivas e há uma maior possibilidade de que um objetivo seja alcançado.

Logo, os mapas mentais podem ser usados com eficiência no gerenciamento de informações em reuniões, em planejamentos, na geração de ideias e na organização de apresentações. Um mapa mental é o instrumento perfeito de comunicação, administração e desenvolvimento eficiente de projetos profissionais (BUZAN, 2009).

\section{Estudo de caso: aplicação do mapa mental no processo de design em uma APAC}

A pesquisa de mestrado de uma das autoras deste artigo foi desenvolvida na Escola de Design da Universidade do Estado de Minas Gerais, no período de maio a dezembro de 2017, pelo CIDS (Centro Integrado de Design Social) e teve o financiamento de uma bolsista do PAPq, outra autora do presente estudo. A pesquisa aplicou métodos, ferramentas e competências do design com um grupo de presos de uma APAC (Associação de Proteção e Assistência ao Condenado), um modelo alternativo do sistema prisional convencional, que se dedica à ressocialização do indivíduo na sociedade, por meio da humanização da pena de prisão, valorização do ser humano e a evangelização. A APAC, campo deste estudo, está localizada no município de Santa Luzia, Minas Gerais.

O desenvolvimento da pesquisa contou com visitas a campo, ocorridas quinzenalmente no regime fechado. A participação dos recuperandos ocorreu por livre interesse, tendo assim grupos maiores no início das oficinas e um afunilamento no decorrer do projeto, conforme o engajamento dos participantes. As oficinas ocorreram no auditório da APAC, onde as cadeiras eram dispostas em semicírculo de forma a auxiliar na participação e interação entre os participantes.

A aplicação da ferramenta mapa mental no processo se deu na terceira oficina, e teve como objetivo conhecer o grupo formado e identificar os recursos presentes dentro da associação para a criação do projeto. Dessa forma, buscou-se levantar as habilidades dos participantes, possíveis contatos, problemas e ideias. A escolha da ferramenta mapa mental para esse encontro se deu exatamente por suas características de organização de pensamento e facilitação da dinâmica de grupo.

Como preparação para a oficina foram realizadas pesquisas teóricas sobre a ferramenta 
mapa mental e seus fundamentos para melhor aplicabilidade e direcionamento. Além disso, houve a compra de materiais (post-its e canetas coloridas) para a execução da oficina.

Um grupo de 11 apenados participou da atividade. Para a aplicação da ferramenta mapa mental em grupo, foi utilizada também a ferramenta brainstorming (tempestade de ideias), para uma maior abertura no lançamento de ideias e associações.

Inicialmente, foi realizada a apresentação de algumas regras do brainstorming, como: o não julgamento ou crítica das ideias dos participantes, expor todas as ideias que surgirem e ter o máximo de ideias possíveis. Posteriormente, houve a realização de uma dinâmica, como forma de ensino sobre o funcionamento da ferramenta brainstorming e estímulo para a geração de ideias, a fim de espairecer e aproximar a interação entre os participantes. A dinâmica se dividiu em duas etapas, a primeira na qual cada participante teve de pensar duas funções de um lápis e a segunda em que coletivamente, o grupo pensou no máximo de funções possíveis. Essa dinâmica auxiliou a demonstrar para os participantes o potencial que o trabalho coletivo tem de incentivar a criatividade e apresentar o funcionamento de um brainstorming. Nota-se que os participantes se interessaram pela dinâmica, colaborando ativamente. Além disso, ela serviu como preparação para que os participantes se soltassem, ficando mais à vontade durante o desenvolvimento do mapa mental.

Em seguida foi feita uma apresentação teórica da ferramenta mapa mental, com exemplos, a fim de explicar o procedimento que iríamos seguir na sua construção coletiva. Ao apresentar o mapa mental, as pesquisadoras questionaram se algum dos participantes conhecia o termo e o que pensavam que isso poderia ser. Esta prática é importante para evitar uma postura que pressuponha que os participantes não têm conhecimentos prévios.

Foram distribuídos blocos adesivos (post-its) e canetinhas para que os participantes pudessem escrever e colocar suas observações em um mural posto na parede. Foi dada também a opção de que as organizadoras da oficina escrevessem nos post-its, para evitar constrangimentos caso algum participante não soubesse ou conseguisse escrever bem.

O desenvolvimento do mapa mental começou com o levantamento das habilidades e conhecimentos do grupo. Foi necessário o incentivo para que todos participassem e se sentissem incluídos, quesito importante para um projeto participativo, que depende do compartilhamento. Ao término do preenchimento das habilidades e conhecimentos, as pesquisadoras leram em voz alta todos as notas adesivas, buscando valorizar o conteúdo de cada um.

Em seguida, foi pedido para que os recuperandos pensassem nos recursos existentes na APAC que estavam disponíveis para o projeto de design que se iniciava. Foram levantados também pessoas-chave, contatos e possíveis parceiros que poderiam ajudar no projeto. Muitos apoiadores, voluntários e pessoas que trabalham na instituição foram citados. Por fim, foi solicitado que o grupo levantasse demandas, problemas e oportunidades existentes na APAC.

No processo de levar esses pontos-chave estabelecidos, surgiram algumas ideias para o projeto. A fim de não se perder essas sugestões, nem desestimular o pensamento criativo dos participantes, foi incluída uma nova ramificação no mapa mental: ideias. Esse ramo pôde ser preenchido a qualquer momento da dinâmica do mapa mental.

Desse modo, o conceito central do mapa mental foi "recursos para o projeto" e os subconceitos abordados foram: habilidades, contatos, recursos da APAC, problemas e ideias. A 
figura 4 mostra o mapa mental desenvolvido na APAC e a figura 5 apresenta versão digital do mapa mental.

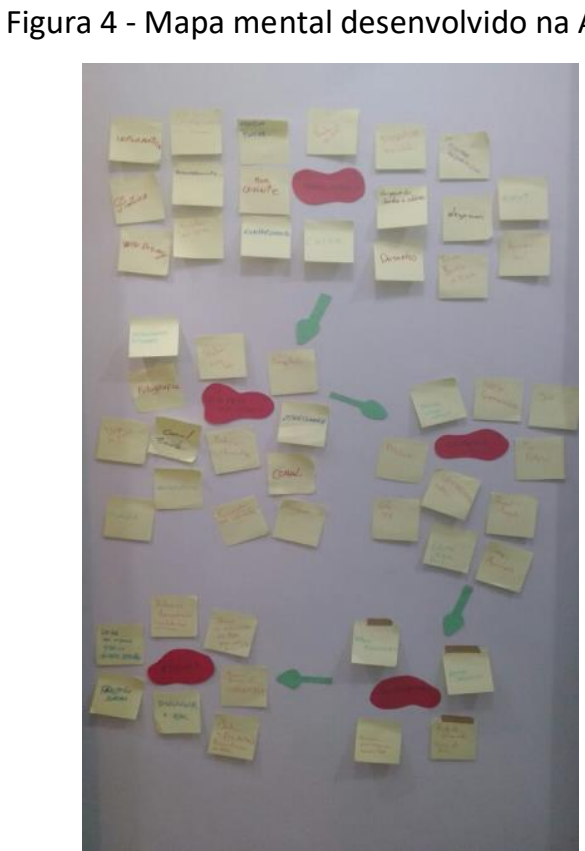

Fonte: $\mathrm{O}$ autor

Figura 5 - Mapa mental desenvolvido na APAC e digitalizado

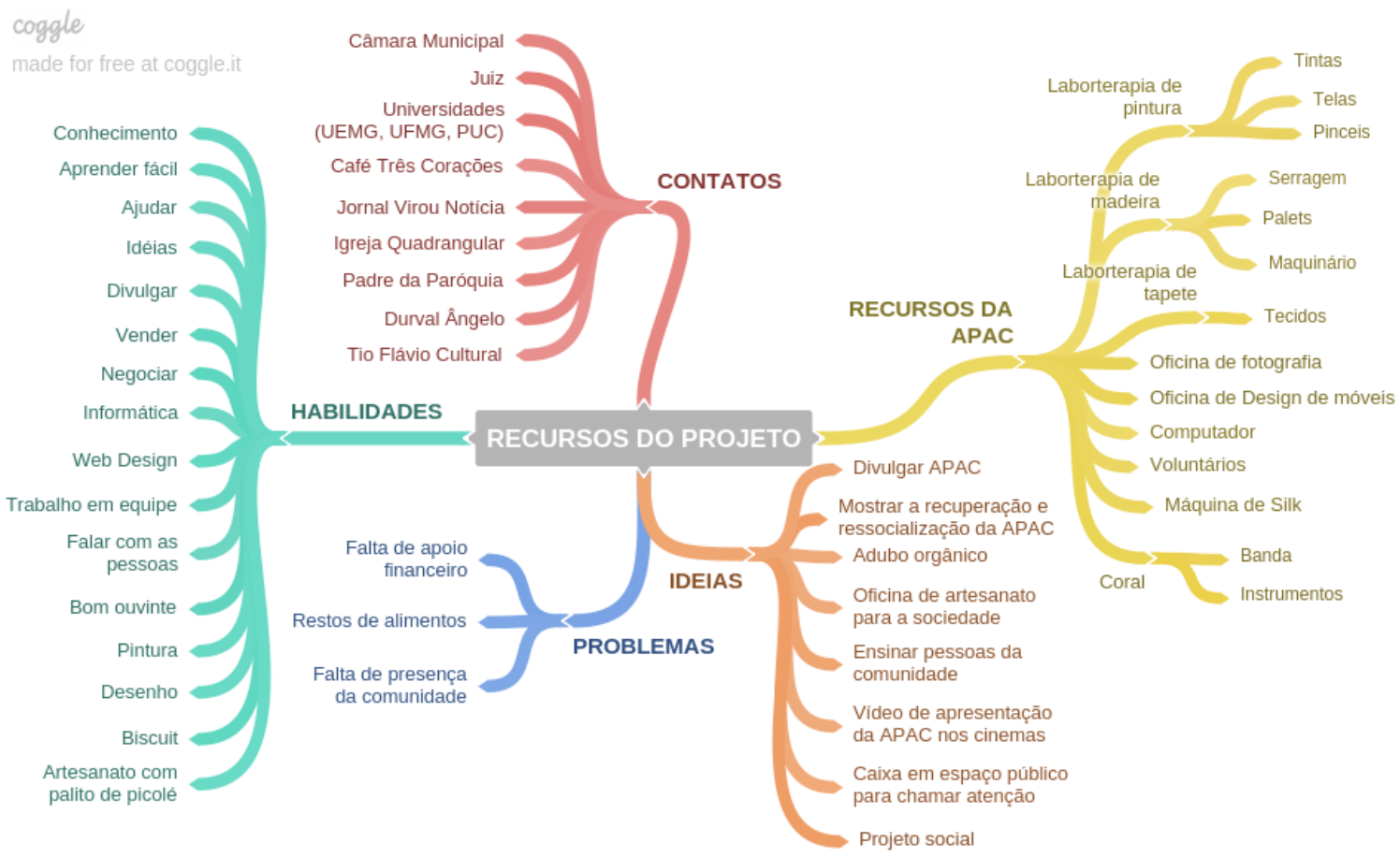

Fonte: $\mathrm{O}$ autor 
Nota-se que o mapa mental permitiu que houvesse uma maior organização visual durante o levantamento dos tópicos e que possivelmente ela colaborou para que a equipe prosseguisse criativa durante o processo. Assim, a ferramenta se mostrou adaptada para essa etapa do projeto e gerou uma síntese que concentra informações. Percebe-se que o estabelecimento de temas centrais para conduzir o mapa mental foi de extrema importância para a dinâmica.

Observa-se que as setas e cores utilizadas no mapa mental físico e digitalizado auxiliam na identificação das informações principais e na criação de associações. Esses elementos guiaram o olhar das pessoas e facilitam o acesso rápido à informação, melhorando a compreensão dos dados levantados e proporcionando um bom entendimento do todo.

Finalizando a oficina, as pesquisadoras pediram retorno dos participantes sobre o que poderia ser melhorado. Um deles se posicionou afirmando que considera o uso de post-its pouco ecológico, pelo desperdício de papel.

Como um todo, pode-se dizer que a ferramenta mapa mental se mostrou útil ao projeto, pois trouxe informações, ideias e as sistematizou de forma clara, fazendo com que todos no grupo tivessem uma ampla visão sobre o projeto: quais problemas seriam abordados, quais ideias trabalhadas, quem seriam os contatos-chave, quais habilidades poderiam ser utilizadas e quais materiais e ferramentas teriam acesso para a realização do projeto. A organização do pensamento, proporcionado pelos mapas mentais, auxiliou em um melhor desenvolvimento do pensamento criativo. Com a realização dos mapas mentais, pode-se entender o contexto e identificar problemas, que foram focados durante o processo de design.

\section{Conclusões}

Os mapas mentais podem ser considerados adequados para a aplicação durante o método de design, por suas inúmeras similaridades ao que é exigido do designer como profissional. Essa ferramenta leva a uma boa organização, encadeamento e integração de informações, principalmente de ideias, capacidades de extrema relevância em um processo de design.

Ressalta-se que os mapas mentais estimulam uma visão ampla e holística, proporcionando uma compreensão mais abrangente do problema trabalhado, o que é ideal para lidar com problemas complexos, que cada vez mais se tornam o foco do design na atualidade. Por suas características, os mapas mentais podem, inclusive, facilitar a percepção de possíveis soluções, uma vez que, utilizando a ferramenta, as alternativas se tornam mais visíveis e as tomadas de decisões podem ser mais assertivas, considerando todo o contexto e as diversas opções existentes.

Observa-se que os mapas mentais são benéficos para trabalhos em grupo, pois facilitam a comunicação entre os participantes e organizam todas as contribuições em um único painel. Essa ferramenta facilita na inclusão dos participantes no processo de forma igualitária, os estimulando a contribuir na construção do conhecimento coletivo. Dessa maneira, ela é indicada para processos de design participativos, que pretendem envolver diversos usuários.

A partir da experiência do estudo de caso, nota-se que o mapa mental é uma ferramenta apropriada para aplicação no começo de um processo de design, uma vez que auxilia a ter uma visão ampla e significativa do contexto. Além disso, sua organização não linear é alinhada ao pensamento criativo, podendo ser usada em momento de ideação e juntamente com o 
brainstorming. Dessa forma, por meio do mapa mental, é possível identificar problemas e também gerar ideias, direcionando o projeto de design e levantando fundamentos para as tomadas de decisões.

\section{Referências}

AMORETTI, M. S. M.; TAROUCO, L. M. R. Mapas conceituais: modelagem colaborativa do conhecimento. Informática na Educação: teoria e prática, v. 3, n. 1, 2000. Disponível em: <http://seer.ufrgs.br/InfEducTeoriaPratica/article/view/6412/3854>. Acesso em: 25 fev. 2018.

AVENDAÑO, L. E. C.. A Importância do Ensino da Gestão do Design. Revista Belas Artes, 2011, p.1. Disponível em: <http://www.belasartes.br/revistabelasartes/downloads/artigos/4/a-importancia-doensino-da-gestao-do-design.pdf>. Acesso em: 28 fev. 2018.

BELLUZZO, Regina Célia Baptista. Construção de mapas: desenvolvendo competências em informação e comunicação. 2. ed. Bauru: Cá entre Nós, 2007.

BONINI, L. A.; SBRAGIA, R.. Modelo de design thinking como indutor da inovação nas empresas: um estudo empírico. Revista de Gestão e Projetos - GeP, São Paulo, v. 2, n. 1, , jan/jun, 2011.p. 03-25.

BOVO, V. HERMANN, W.. Mapas Mentais - Apresentação e Exemplos. In: BOVO, Viviani; HERMANN, Walther. Mapas Mentais: Enriquecendo Inteligências. 2005. Disponível em: <www.idph.net/loja/pedidos.shtml>. Acesso em: 26 fev. 2018.

BRUSSI, M. T.. O Design Thinking como metodologia no processo de escolha e uso dos instrumentos de comunicação organizacional. Universidade de Brasília, Brasília, 2014.

BROWN, T.. Design: How design thinking transforms organizations and inspires innovation. New York: Harper Business, 2009.

BUZAN, T.. Mapas Mentais. Rio de Janeiro: Sextante, 2009.

BUZAN, Tony. Mapas Mentais e sua elaboração: um sistema definitivo de pensamento que transformará a sua vida. São Paulo: Culttrix, 2002.

BUZAN, T.; BUZAN, B.. The Mind Map Book: how to use radiant thinking to maximize your brain's untapped potential. Londres: Penguin Books, 1994.

CAIN, S. O poder dos quietos: como os tímidos e introvertidos podem mudar um mundo que não para de falar. Rio de Janeiro: Nova Fronteira Participações S.A, 2012.

DELL'ISOLA, A.. Mentes brilhantes. São Paulo: Universo dos Livros, 2012.

DESIGN COUNCIL. Design methods for developing services. Inovate UK, Keeping Connected Business Challenge. 2007. Disponível em: <https://connect.innovateuk.org/documents/ 3338201/3753639/Design+methods+for+developing+services.pdf/3db0636e-6acc-4de4-9db63f25d1194bca>. Acesso em 20 fev. 2018.

EDEN, C.. Messing about problems.Pergamon: Oxford, 1983.

FRANZATO, C.. O processo de inovação dirigida pelo design: um modelo teórico. Redige, v. 2, n. 1, 2011. p. 50-62. Disponível em: <https://slidex.tips/download/o-processo -de-inovaao-dirigidapelo-design-um-modelo-teorico>. Acesso em 27 fev. 2018. 
KRUKEN, L.. Design e território: valorização de identidades e produtos locais. Studio Nobel, 2009.

NUNES, P. Brainstorming, 2008. Disponível em: <http://knoow.net/ciencecon empr/gestao/brainstorming/>. Acesso em: 12 mar. 2018.

PINHEIRO, T.; ALT, L.. Design thinking Brasil: empatia, colaboração e experimentação para pessoas, negócios e sociedade. Rio de Janeiro: Elsevier, 2011.

ONTORIA PEÑA, A.; LUQUE, A de.; GÓMEZ, J. P. R.. Aprender com mapas mentais: uma estratégia para pensar e estudar. 3. ed. São Paulo: Mandras, 2008.

SILVA, A. M.. 0 que são mapas mentais. 2009. Disponível em: <http://www.administradores.com.br/artigos/economia-e-financas/o-que-sao-mapas-

mentais/28259/>. Acesso em 03 mar. 2018.

SILVA, E. L. da; MENEZES, E. M. . Metodologia da pesquisa e elaboração de dissertação. 4. ed. rev. atual. - Florianópolis: UFSC, 2005.

GOULART, M. C. F.; MERINO, E. A. D.. Uso de representações visuais construídas colaborativamente como estratégia de ensino em gestão de design. Florianópolis: Ed. Graphica, 2013.

TEIXEIRA, M. B. S.. O que é design. Belo Horizonte: SEBRAE/MG, 2009.

VILELA, V. V.. Benefícios e vantagens de mapas mentais. Disponível em <http://www.mapasmentais.idph.com.br/textos/beneficios_e_vantagens_de_mapas_mentais.ph p\#.WsFYkojwblU>. Acesso em: 15 mar. 2018. 